\title{
Enhanced Biodegradation of HMW- PAHs using Immobilized Microorganisms in an Estuarine Reed Wetlands Simulator
}

\author{
Ruying Huang, Weijun Tian*, Huibo Yu \\ Ocean University of China, Qingdao,Shandong,China
}

Keywords: Pyrene; Indeno(1,2,3-cd)pyrene; Biodegradation; Immobilized; Reed

\begin{abstract}
Biodegradation of pyrene and indeno(1,2,3-cd)pyrene in reed rhizosphere soil was carried out in a small-scale wetland simulator using reed as well as microorganisms immobilized on cinder beads under natural environmental conditions. The results show that the stability of the introduced strains was enhanced upon immobilization and that the depletion of pyrene and indeno(1,2,3-cd)pyrene after 40 days was $68.4 \%$, and $87.9 \%$, respectively, whereas reeds or immobilized cells alone exhibited relatively poor degradation of PAHs in the same time period. This showed that plant and microbes promoted the degradation of pyrene and indeno(1,2,3-cd)pyrene. The results of this study show that PAH-degrading bacteria associated with plants could enhance pollutant removal, and this offers opportunities to facilitate high molecular weight (HMW) PAHs plant-microbe remediation in wetlands.
\end{abstract}

\section{INTRODUCTION}

Polycyclic aromatic hydrocarbons (PAHs) are compounds composed of two or more fused aromatic rings[Haeseler et al., 1999]. PAHs in soil have recently become of great concern due to their potential toxicity, carcinogenicity, mutagenicity and persistence[Fujikawa et al., 1993]. However, high molecular weight (HMW) PAHs with more than four rings are highly hydrophobic, minimally bioavailable, and more recalcitrant. Traditionally, their fate in the wetland is associated with both abiotic and biotic factors including volatilization, photooxidation, adsorption to soil particles, chemical oxidation, and biological processes[Seo et al., 2007]. Biotransformation is thought to be the principal and most promising mechanism. Thus, bioaugmentation treatments involving selected plants or microorganisms have been proposed.

The Liaohe estuarine delta, which has the largest reed (Phragmites communis Trin) population in Asia and is an important petroleum producer, has inadvertently suffered PAH contamination. The initial studies on PAH distribution in the Liaohe reed wetland showed a concentration of $\sum$ PAHs (the sum of 16PAHs listed as priority pollutants by the United States Environmental Protection Agency (USEPA)) at a depth of $10 \mathrm{~cm}$ of $963.25 \mathrm{ng} / \mathrm{g}$ [Tian et al., 2014]. The PAHs (4-, 5-, 6-benzene rings) with a high molecular weight (HMW) that resist biological degradation comprised $50 \%$. This concentration was higher in estuarine wetlands in China, and the distribution changes from month to month were not obvious. This shows that the activity of the degraders of PAHs was weak in natural wetlands, although the reed rhizosphere exudates appeared to favor microbial activity. Therefore, in this study, we chose pyrene and indeno(1,2,3-cd)pyrene as targeted PAHs and aimed to study the effects of reeds and of immobilized bacteria on pyrene and indeno(1,2,3-cd)pyrene degradation during the simulator experiment.

\section{MATERIALS AND METHODS}

\section{Oil- contaminated Soil}

For pyrene and indeno(1,2,3-cd)- pyrene degradation, petroleum- contaminated soil samples were obtained from the oil-contaminated Liaohe estuarine wetland in Panjin, Liaoning Province, China.

\section{Immobilization of Bacterial Cells}

Bacteria were immobilized using the method of embedding. Cinder powder was used as a carrier material to immobilize bacteria due to its properties of being porous, nontoxic to bacteria, recycled, 
and inexpensive.

\section{Degradation Ability of Immobilized Bacterial Cells Study}

Long-term crude oil exploitation and petroleum hydrocarbon pollution cause severe environmental disturbances in Liaohe estuarine wetlands, and soil from this site was used for carrying out small-scale simulator studies to determine the degradation abilities of the immobilized cells and reed. The simulator measuring $100 \mathrm{~cm} \times 50 \mathrm{~cm}$ and that was $50 \mathrm{~cm}$ deep was made of PVC. The wetland simulator was divided into four plots as described below:

Plot A: Reeds obtained from Liaohe estuarine wetlands were planted in this soil. Rhizosphere soil were mixed with $300 \mathrm{~g}$ of cinder beads with immobilized bacteria when the reeds had a height of $\sim 40 \mathrm{~cm}$.

Plot B: Only reeds obtained from Liaohe estuarine wetlands were planted in this soil.

Plot C: Only soil mixed with 300 g of cinder beads with immobilized bacteria.

Plot D: Soil without cinder beads or reeds. This served as the control.

Ten grams of soil samples was collected from a depth of $\sim 10 \mathrm{~cm}$ using a soil collecting pipe from three different random positions for further analysis. The sampling was done at the following time points: $0,2,4,6,10,20,30$, and 40 days.

Analysis of Pyrene and Indeno(1,2,3-cd)pyrene Remaining Concentration

Soil samples were extracted for pyrene and indeno(1,2,3-cd)pyrene in simulator study and analyzed for residual PAHs by GC-MS analysis with an Agilent 6890 Gas Chromatograph (DB-5 column $30 \mathrm{~m} \times 0.25 \mathrm{~mm}$ ID $\times 0.25 \mu \mathrm{m}$ film thickness) coupled to an Agilent 5975 mass spectrometer, as described by Zhao et al.[ Zhao et al., 2014]

\section{RESULTS AND DISCUSSION}

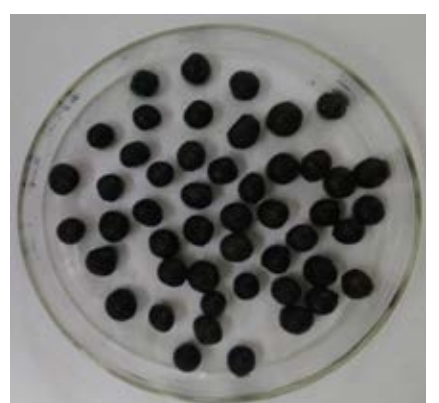

Figure 1. Cinder beads entrapped with cells of PAHs degraders.

PAHs degraders were entrapped in cinder beads with diameter of 6-8mm (Figure 1.).

Small-scale wetland simulator studies were carried out to determine the efficiency of PAH degradation under actual environmental conditions from

the middle of September to the end of

October.
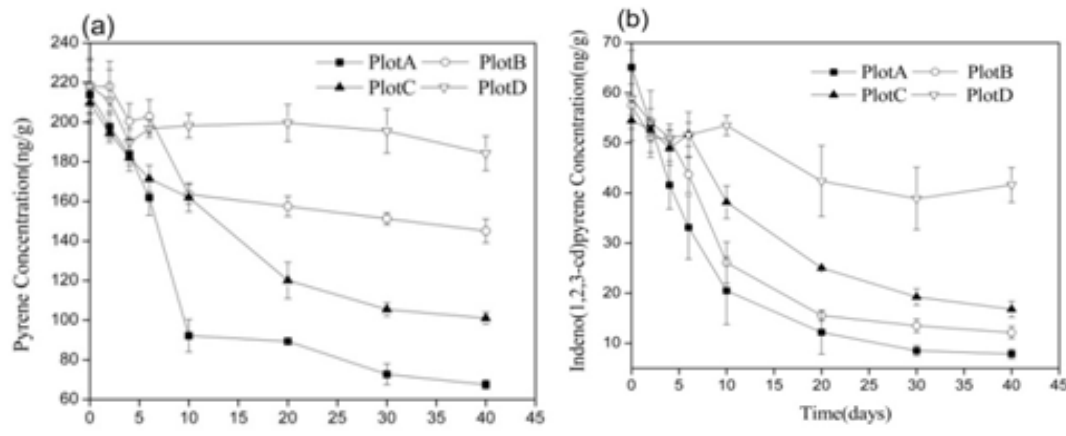

Figure 2. Wetland simulator studies on PAHs depletion by reeds and strains immobilized on cinder beads as a function of time. Plot A : reeds and immobilized cells; Plot B : reeds alone; Plot C: immobilized cells alone; Plot D: control plot. Error bars represent standard errors of means.

Figure 2 indicates the depletion of PAHs in the wetland simulator under different treatments with respect to time. In plot A containing petroleum- contaminated soil, bioaugmented reeds and 
immobilized cells of strains on cinder beads, 56.89\% pyrene was depleted within 10 days. The initial rate of pyrene degradation was quite slow, and only $24.27 \%$ pyrene was degraded in the first 6 days. However, on the tenth day, there was an increase in the rate of pyrene degradation from an initial concentration of $214 \mathrm{ng} / \mathrm{g}$ to $92 \mathrm{ng} / \mathrm{g}$. For indeno(1,2,3-cd)pyrene degradation, a similar pattern of slow initial degradation was observed, and 36\% depletion occurred in the first 4 days. After the fourth day, indeno(1,2,3-cd)- pyrene quickly degraded to $20.5 \mathrm{ng} / \mathrm{g}$ from $41.6 \mathrm{ng} / \mathrm{g}$, indicating a 50.75\% depletion over the next 6 days. Degradation of pyrene and indeno(1,2,3-cd)pyrene showed similar trends in Plot B containing reeds alone with a slow depletion during the whole experiment period. However, pyrene and indeno(1,2,3-cd)pyrene removals were relatively fast with respective rates of $33 \%$ and $78 \%$ in Plot B. Apparently, $\mathrm{PAH}$ degradation of bacteria immobilized on cinder beads(Plot $\mathrm{C}$ ) was enhanced over that of the control. In contrast, as shown in Plot $\mathrm{D}$, there was only a slight decrease in the control plots, with pyrene and indeno(1,2,3-cd)pyrene depletion occurring to the extent of only approximately $10-30 \%$ even after 40 days, indicating that a negligible amount of PAHs is degraded by indigenous microorganisms or abiotic factors in the soil.

Wetland simulator studies were carried out to show the efficiency of the process on a small scale. We were able to successfully demonstrate that the bioremediation of PAH-contaminated soil by bioaugmenting with reeds and immobilized cells of strains resulted in the greatest depletion of pyrene and indeno(1,2,3-cd)pyrene within 40 days. It is speculated that its success was probably linked to its ability to immobilize and enrich PAH degraders, initiate co-metabolism, and improve PAH bioavailability[Yap et al., 2010]. In contrast, only reeds were found to degrade pyrene and indeno(1,2,3-cd)- pyrene at a slower rate, which may have been brought about by sorption of PAHs to the roots, plant metabolism[Leigh et al., 2006] or enhanced degradation through the rhizospheric bacteria and/or promotion of indigenous degraders [Huang et al., 2004]. Similarly, the reduction of PAHs by immobilized cells alone was not significant. Therefore, it can be reasonably hypothesized that changes in the abundance of degraders or PAH bioavailability induced by the reed rhizosphere associated with immobilized cells would mainly determine PAH degradation[Read et al., 2003]. In the control soils, pyrene and indeno- (1,2,3-cd)pyrene degradations proceeded to the extent of $10 \%-30 \%$ after 40 days, which could be due to the photooxidation/volatilization of PAHs from the soil[Wong and Bidleman, 2011], indigenous microbial activities or abiotic factors including particle adsorption, TOC, oxygen, and moisture. Soil temperature, $\mathrm{pH}$, and salinity are also important parameters that affect microbial activity and metabolism, which affect the rate and extent of bioremediation.

\section{CONCLUSION}

This study has shown that bioaugmentation with reeds and mixed strains stimulated degradation of PAHs in small-scale natural conditions. The bioaugmentation may offer a solution for treating contaminated soil where the PAH concentration is too slow to be depleted. The wetland studies have shown that the introduction of immobilized PAH-degradation bacteria to contaminated soil could deplete most PAHs under appropriate conditions, which plays an important role in determining the success of remedial strategy. Our findings provide insight into plant-microbe remediation in estuarine wetlands and can serve as a model study for effective degradation of other, more complex or structurally related organic compounds in actual contaminated sites.

\section{Acknowledgments}

This study was supported by the Natural Science Foundation of Shandong Province of China (ZR2014EEM016).

* Corresponding author at: Ocean University of China, College of Environmental

Science and Engineering, 238\# Songling Road, Qingdao 266100, PR China. 


\section{REFERENCES}

1. Fujikawa, K.; Fort, F. L.; Samejima, K.; Sakamoto, Y. Genotoxic potency in drosophila melanogaster of selected aromatic amines and polycyclic aromatic hydrocarbons as assayed in the DNA repair test. Mutat. Res.1993, 290, 175-182.

2. Haeseler, F.; Blanchet, D.; Druelle, V.; Werner, P.; Vandecasteele, J. P. Ecotoxicological assessment of soils of former manufactured gas plant sites: bioremediation potential and pollutant mobility. Environ. Sci. Technol. 1999, 33, 4379-4384.

3. Huang, X.-D.; El-Alawi, Y.; Penrose, D. M.; Glick, B. R.; Greenberg, B. M. Multi-process phytoremediation system for removal of polycyclic aromatic hydrocarbons from contaminated soils. Environ. Pollut. 2004, 130, 465-476.

4. Leigh, M. B.; Prouzová, P.; Macková, M.; Macek, T.; Nagle, D. P.; Fletcher, J. S. Polychlorinated biphenyl(PCB)-degrading bacteria associated with trees in a PCB- contaminated site. Appl. Environ. Microbiol. 2006, 72, 2331-2342.

5. Read, D.B.; Bengough, A. G.; Gregory, P. J.; Crawford, J. W.; Robinson, D.; Scrimgeour, C. M.; Young, I. M.; Zhang, K.; Zhang, X. Plant roots release phospholipid surfactants that modify the physical and chemical properties of soil. New Phytol. 2003, 157, 315-326.

6. Seo, J. S.; Keum, Y. S.; Harada, R. M.; Li, Q. X. Isolation and characterization of bacteria capable of degrading polycyclic aromatic hydrocarbons (PAHs) and organophosphorus pesticides from PAH-contaminated soil in Hilo, Hawaii. J. Agric. Food Chem. 2007, 55, 5383-5389.

7. Tian, W.; Zhao, Y.; Sun, H.; Bai, J.; Wang, Y.; Wu, C. The effect of irrigation with oil-polluted water on microbial communities in estuarine reed rhizosphere soils. Ecol. Eng. 2014,70, 275-281.

8. Wong, F.; Bidleman, T. F. Aging of organochlorine pesticides and polychlorinated biphenyls in muck soil; Volatilization, bioaccessibility, and degradation. Environ. Sci. Technol. 2011, 45, 958-963.

9. Yap, C.L.; Gan, S.; Ng,H. K. Application of vegetable oils in the treatment of polycyclic aromatic hydrocarbons-contaminated soils. J. Hazard. Mater. 2010, 177, 28-41.

10. Zhao, Y.; Hong, B.; Fan, Y.; Wen, M.; Han, X. Accurate analysis of polycyclic aromatic hydrocarbons (PAHs) and alkylated PAHs homologs in crude oil for improving the gas chromatography/mass spectrometry performance. Ecotoxicol. Environ. Saf. 2014,100, 242-250. 